\title{
1 Detecting gas flares and estimating flaring volumes at 2 individual flow stations using MODIS data
}

\author{
Obinna C.D Anejionu, G. Alan Blackburn and J. Duncan Whyatt \\ Lancaster University, Lancaster Environment Centre, United Kingdom; \\ Email: o.d.anejionu@lancaster.ac.uk
}

Gas flaring has gained global recognition as a prominent agent of pollution, leading to the establishment of the Global Gas Flaring Reduction (GGFR) initiative, which requires an objective means of monitoring flaring activity. Because auditable information on flaring activity is difficult to obtain there have recently been attempts to detect flares using satellite imagery, typically at global scales. However, to adequately assess the environmental and health impacts of flaring from local to regional scales, it is important that we have a means of acquiring information on the location of individual active flaring sites and the volume of gas combusted at these sites. In this study we developed an approach to the retrieval of such information using nighttime MODIS thermal imagery. The MODIS flare detection technique (MODET) and the MODIS flare volume estimation technique (MOVET) both exploit the absolute and contextual radiometric response of flare sites. The levels of detection accuracy and estimation error were quantified using independent observations of flare location and volume. The MODET and MOVET were applied to an archive of MODIS data spanning 2000-2014 covering the Niger Delta, Nigeria, a significant global hotspot of flaring activity. The results demonstrate the substantial spatial and temporal variability in gas flaring across the region, between states and between onshore and offshore sites. Thus, while the estimated total volume of gas flared in the region over the study period is large (350 Billion Cubic Metres), the heterogeneity in the flaring indicates that the impacts of such flares will be highly variable in space and time. In this context, the MODET and MOVET offer a consistent and objective means of monitoring flaring 
27 activity over an appropriate range of scales and it is now important that their robustness and trans-

28 ferability is tested in other oil-producing regions of the world.

29 Keywords: Gas Flare, Thermal Infrared Remote Sensing, MODIS Flare Detection, Niger Delta, 30 Gas Flaring Volume

31 


\section{Introduction}

Gas flaring is one of the processes, alongside venting and reinjection, used to dispose of the natural gas associated with extracted crude oil. Crude oil from a group of wells in an oil field is initially gathered for processing at a flow station where gas is separated from oil. One or a number of flares in the vicinity of the flow station are then used to burn off the gas. Flaring is commonly adopted by oil companies because it is more cost-effective than converting to commercial natural gas. Efforts to empirically assess the environmental impacts of flaring are frequently hampered by limited access to official information on flare locations and volumes, the heterogeneity in spatial and temporal sampling strategies and methods used to collect data and lack of auditability. In order to begin to assess the environmental impacts of flaring in a coherent fashion, there is a pressing need for a robust, consistent and objective means of determining: where active flaring sites are located; what volume of gas is being flared at each site; and how the distribution and volume of flares has changed over space and time. Consequently, there is a need to develop new methods of acquiring such information, and remote sensing seems the most viable option. However, as explained below, while there have been several approaches developed for monitoring biomass fires, only a limited number of studies have attempted to map flares or estimate flaring volumes from space. The present study builds upon this work and presents an alternative and enhanced approach.

\subsection{Fire detection using satellite imagery}

Satellite systems have long been deployed to detect and monitor fires and their effects, due to their timely and repetitive observations, multispectral viewing capabilities, synoptic coverage, and their ability to retrieve information from hazardous locations. Four major classes of algorithm (single channel threshold, multi-channel threshold, contextual and sub-pixel) have been developed to sense fires from satellite images (Li et a.l, 2000, Martin et al., 1999). The two main types of signals employed for this purpose are either direct (flames and heat) or indirect (smoke and burned surfac- 
es). Direct signals are most commonly employed in fire detection studies (Movaghati et al., 2009, Justice et al., 2006, Weaver et al., 2004), whilst indirect signals are employed for post fire assessment and management (Sedano et al., 2013; Lanorte et al., 2011). Most satellite-based fire detection studies have focused on forest/biomass fires, as their impacts draw considerable attention from the research community and investigations are facilitated by the availability of well-established firehotspot algorithms (ATPS, 2013; Wooster et al., 2012; Wang et al., 2012; Xu et al., 2010; Casadio and Arino, 2009; Qian et al., 2009; Roberts and Wooster, 2008; Zhukov et al., 2006; Giglio et al., 2003; Prins and Menzel, 1992; Dozier, 1981).

Radiation emitted at typical surface fire temperatures mostly lies in the infrared region of the electromagnetic spectrum. Thus, images from sensors such as the Advanced Very High Resolution Radiometer (AVHRR), the Moderate Resolution Imaging Spectroradiometer (MODIS), and the Geostationary Operational Environmental Satellite (GOES) Imager, which have infrared bands, have commonly been used for forest fire detection (Justice et al., 2006; Ichoku et al., 2003; Li et al., 2000; Kaufman et al., 1998). These systems have a relatively high temporal resolution, enabling near-continuous monitoring of active fire fronts, which is very important given the ephemeral nature of biomass fires.

The AVHRR was used to produce the first global fire product and near-real-time global fire data set. The fire detection capability of AVHRR nighttime imagery was first applied on fixed targets of known location (Matson and Dozier, 1981). The level of success achieved in the detection of fixed fire sources led to the use of AVHRR in biomass fire detection. The MODIS sensor has 36 spectral bands, some of which are specifically designed for fire monitoring and has improved fire detection capabilities based on existing algorithms developed for AVHRR (Casanova et al., 2005, Justice et al., 2002). However, gas flaring, has not received as much attention as other high temperature events (biomass fires, volcanoes, over ground and underground coal fires) and existing fire detection algorithms are often inadequate for detecting gas flares due to the small extent of each flare (Anejionu et al., 2014, Elvidge et al., 2011). 


\subsection{Detection of gas flares using satellite imagery}

Croft (1978) was the first to observe gas flares in nighttime Defence Meteorological Satellite Program (DMSP) and Landsat Multi-spectral Scanner System (MSS) images. While carrying out research to determine blackbody temperatures of sub-pixel fires Matson and Dozier (1981) discovered that flares were detectable from nighttime AVHRR imagery. Twelve high temperature industrial sources in Detroit (steel mills), and six gas flares in the Persian Gulf were identified using the $3.8 \mu \mathrm{m}$ and $11 \mu \mathrm{m}$ bands of AVHRR. Muirhead and Cracknell (1984) visually inspected daytime AVHRR images and were able to identify gas flares from North Sea oil rigs.

Elvidge et al. (2007) used DMSP Operational Linescan System (OLS) imagery to visually identify flares, using the circularity and bright centres of lights from flares to aid detection, and this was the first attempt to detect flares on a global scale over extended time periods (1994-2008 inclusive). Although the DMSP-OLS method has high temporal resolution (12 hours revisit period), the relatively low spatial resolution $(560 \mathrm{~m}-2.7 \mathrm{~km})$ of the imagery limits its ability to accurately detect individual flare sites, particularly amidst urban areas as noted by Elvidge et al. (2009a). Furthermore, the visual identification technique employed is subjective and time consuming.

Casadio et al. (2012a) applied an active flame detection algorithm (ALGO3) to nighttime Along Track Scanning Radiometer (ATSR) imagery to detect flares on a global basis. The method is a single band fixed threshold algorithm based on the shortwave infrared band of ATSR $(1.6 \mu \mathrm{m})$ and mostly employs temporal persistence of hotspot pixels as an indicator of flaring activity, with the presence of industrial installations (identified from high resolution images available on Google Earth) used to validate the results. However, the method of validation, which does not utilise direct observation of flares on high resolution images, may be inconsistent as not all industrial sites in oil producing regions contain flares. Nevertheless, ALGO3 is more objective than the DMSP-OLS and AVHRR methods, as it adopts a fixed threshold method to automatically discriminate hotspots, thus overcoming the limitations of manual identification. The method has subsequently been revised 
through the integration of nighttime ATSR and SAR products to detect flares in the North Sea

109 (Casadio et al., 2012b).

Whilst the DMSP-OLS and ATSR methods of flare detection can be useful for detecting

111 flares at global level, they are of more limited utility where precise information on flare locations 112 and flare volumes is required for accurate assessment of impacts from local to regional scales. In 113 our previous work, we exploited the higher spatial resolution of Landsat imagery and its extended 114 time-series to detect flares over a period of 29 years (Anejionu et al., 2014). We developed the 115 Landsat Flare Detection Method (LFDM), a multiband threshold technique that used the near infrared, shortwave infrared and the thermal infrared bands to map active gas flares in the Niger Delta.

117 The LFDM achieved a higher level of spatial accuracy $( \pm 23.85 \mathrm{~m})$ than earlier methods based on 118 low resolution imagery, and the long archive enabled us to reconstruct the flaring history of the re119 gion back to 1984. However, despite the success of the LFDM in flare detection, the low frequency 120 of cloud-free images over the region, lack of nighttime data, and the scan line corrector error in post 1212003 images limited its potential for estimating flaring volumes.

In an attempt to identify alternative data sources that may overcome some of the problems associated with Landsat data, we noted that Elvidge et al. (2011) had demonstrated some potential for using MODIS imagery to detect flare sites; this prompted us to investigate this data further. A key advantage of MODIS data is the frequency of acquisition from the Terra and Aqua satellite platforms, which increases the likelihood of obtaining cloud-free imagery, which is a critical constraint at the Niger Delta study site and most other regions of the world. Therefore, the present study explores the use of MODIS imagery for accurately and objectively detecting onshore and offshore flares and for estimating flaring volumes.

\subsubsection{MODIS fire products and gas flare detection}

The MODIS fire products (MOD14 and MYD14) from Terra and Aqua platforms, respective134 ly, were developed for the identification and monitoring of wild fires. The fire detection algorithms 
are based on those developed for AVHRR, but with new capabilities (previous AVHRR 3.75 $\mu$ m waveband was shifted to $3.95 \mu \mathrm{m}$ in MODIS, to minimise the effects of atmospheric water vapour absorption and reflected solar radiation by $40 \%$ (Kaufman et al., 1998)). Fire pixels are retrieved using a hybrid of absolute and contextual processes that involve the application of sets of thresholds on bands $22(3.95 \mu \mathrm{m}), 31(11 \mu \mathrm{m})$ and $16(0.86 \mu \mathrm{m})$ (Giglio et al., 2003; Justice et al., 2002).

However, as observed by Elvidge et al., (2011), the MODIS fire product is less efficient at detecting gas flares because thresholds in the algorithms were adapted to minimise the detections of small fires such as gas flares and to maximise the detection of larger and more intense biomass fires (Kaufman et al., 1998, Justice et al., 2002, Giglio et al., 2003). In addition, the algorithms only detect fires on landmasses (onshore) as they are not expected to occur on water bodies (offshore). This is a significant constraint of the product in the present context because a considerable proportion of flaring activities in the Niger Delta are located offshore. However, ongoing improvements of the MODIS fire product (collection 6) are expected to revise the water mask to facilitate offshore gas flare detection (Giglio et al., 2014; Csiszar et al, 2012). Exploratory investigations (Elvidge et al., 2011) revealed that the MODIS fire products were conservative in flare detection, compared with visual observations directly made from the MODIS band 22 image. This indicates that a bespoke algorithm is required for the detection of gas flares from MODIS imagery.

\subsubsection{Flare volume estimation from satellite imagery}

The first attempt to estimate the volume of gas flared using satellite imagery was conducted by Elvidge et al. (2007), who used nighttime DMSP-OLS imagery to quantify the changes in total annual flaring volume for each of the world's oil producing countries over the period 1995 - 2006.

The technique was further improved and the period of study extended to 15 years (1994 - 2008) by Elvidge et al. (2009a). However, the researchers noted some limitations in the DMSP-OLS technique such as the saturation of the DMSP-OLS visible band due to the brightness of gas flares, as well as the inability of the technique to detect flares in the mid-to-high latitudes in the summer time 
161 due to solar contamination. In addition, the lack of onboard calibration of the DMSP-OLS visible

162 band limits the ability to estimate the total radiative output from flares, and the intercalibration of

163

164

165

166

167

168

169

170

171

172

173

174

175

176 different DMSP-OLS sensors was based on the assumption that electrically generated lights around Sicily, Italy, had remained constant over the period of study (1994-2008) which was not validated. Furthermore, Elvidge et al. (2011) found it very difficult to discriminate flares in lit urban areas and lights from oil facilities other than gas flares are often included in DMSP-OLS signals. These limitations will each contribute to uncertainties in estimates of flaring volume using the DMSP-OLS and suggest that there is value in exploring the potential of alternative remote sensing systems.

The first attempt to estimate flaring volume from MODIS was made by Gallegos et al. (2007). They found that the reference flare sites with known gas flaring volumes were in some cases not detectable with the MODIS data, and therefore concluded that MODIS data would only be marginally useful in estimating daily gas flaring volumes. However, as noted by Elvidge et al., (2011) the researchers did not work with enough MODIS images to test its capability for monthly or annual estimation of gas flaring volumes.

Elvidge et al. (2011) found that the MODIS fire product (MOD14) was inefficient at estimating flaring volumes. In many countries such as Nigeria, estimates were typically $25 \%$ lower than estimates derived from DMSP-OLS imagery due to the undersampling of gas flares by MOD14. Furthermore, for countries in the Amazon such as Bolivia, where biomass fires are common, the volume estimates exceeded those derived from DMSP-OLS due to the erroneous inclusion of other fire sources. However, Elvidge et al. (2011) did find a close correspondence between flare volumes estimates made directly from the difference between MODIS bands 22 and 31, and the results previously obtained from DMSP-OLS for a particular sample year (but as noted previously there are several limitations with the DMSP-OLS technique itself). Therefore, based on this finding, they recommended further exploration of MODIS for flare detection and volume estimation.

In this study, we set out to achieve the following objectives: 
i. develop a technique to detect active gas flare sites from MODIS imagery,

ii. develop a technique to estimate the volume of gas flared from individual flare sites from MODIS imagery,

iii. apply these techniques to the MODIS archive in order to quantify the trajectories of gas flaring activity and flaring volumes in a globally significant gas flaring region.

192

\section{Study Area}

The Niger Delta (Figure 1) is a densely populated region with over 10 million people and covers an area of approximately $70,000 \mathrm{~km}^{2}$ (NPC, 2010). It is the largest source of hydrocarbons in Nigeria (Tuttle et al., 1999) and the region has been greatly impacted by ongoing oil and gas exploration and extraction, which commenced in 1958. Importantly, the Niger Delta is home to the third largest mangrove forest in the world with rich biodiversity (Niger Delta Awareness, 2007). Consequently the Niger Delta is ranked as one of the highest conservation priorities in West Africa (IUCN, 1994) as it provides the natural habitat for a wide variety of endemic coastal and estuarine fauna and flora, supporting over $60 \%$ of the total species in Nigeria (World Bank, 1995, cited in Ugochukwu 2008; IUCN, 1994). Despite its importance, the region is virtually unprotected and as a result has been the focus of increasing research activity in recent years, particularly on the impacts of oil exploitation on the environmental (Bayode et al., 2011; Nwaogu and Onyeze, 2010; Eregha and Irugh, 2009), socio-cultural and economic characteristics of the region (Aghalino and Odeh, 2010; Ajiboye et al., 2009). Among the many activities associated with the oil industry that directly affect the environment, such as oil spillage and fires, deforestation, dredging and associated waste, gas flaring is a prominent agent of pollution in the region (Ovri and Iroh, 2013; Ovuakporaye et al., 2012; Abdulkareem et al., 2012; Dung et al., 2008). However, efforts to empirically assess the environmental impacts of flaring in the Niger Delta have been hampered by limited access to official information on flare locations and volumes and difficulties in undertaking field investigations due to security issues. Thus, previous research has mostly been speculative or restricted to small areas surrounding 
214 individual flares (Obia et al., 2011; Abdulkareem, et al., 2012; Anomohanran, 2012; Oseji, 2011;

215 Odjugo and Osemwenkhae, 2009; Dung et al., 2008). Hence, there is an important need to develop 216 a comprehensive understanding of flaring activity and its impacts in the Niger Delta, particularly 217 given that Nigeria ranks second among gas flaring countries globally (Elvidge et al., 2009). Insert Figure 1 here

\section{Methods}

\subsection{Data and preprocessing}

Day and nighttime MODIS images from the Terra and Aqua platforms were acquired from the NASA's Earth Observing System Data and Information System (EOSDIS) (http://earthdata.nasa.gov/). Having explored the data available for all months of the year, it was found that only data for the months of December and January had acceptable levels of cloud-free coverage as all images in all other months had greater than $50 \%$ cloud coverage. These months fall within the Harmattan weather period, with drier and less humid conditions experienced in the Niger

Delta. This study consequently used MODIS data from these months for the period 2000 to 2014. In total, 1643 MODIS images (899 Terra and 744 Aqua) were obtained and processed for the study. Individual images with greater than $30 \%$ cloud cover were removed, leaving a total of 588 images for further analysis. The MODIS raw DN values were processed with the ENVI MODIS toolkit to derive spectral radiances. All images were georeferenced to the WGS 1984 coordinate system then clipped to the study area. Bi-monthly temporal composites were computed from the data obtained in the adjacent months of December and January using a maximum value compositing technique that selected the maximum radiance from each pixel from all the images in the bi-monthly stack (Stoms et al., 1997). This approach records the radiance value for each pixel which is least attenuated by cloud cover and therefore effectively generates a cloud-free composite image and minimises noise mospheric conditions over the study sites on the various image acquisition dates, the compositing 
technique provided a practical and effective atmospheric correction method as has been well estab-

240 lished and previously applied to MODIS data (Huete et al., 2002; Holben, 1986). This procedure 241 generated 15 temporal composite images of the study site covering the 2000-2014 period at an ap242 proximately annual sampling interval.

\subsubsection{Examination of the flare detection potential of MODIS bands}

Each MODIS band was examined interactively and compared to reference data of known flare locations (see section 3.2.1 below) in order to determine its suitability for flare detection. Only a small number of bands showed any capabilities for flare detection (Figure 2, see Table 1 for band characteristics). The daytime shortwave infrared (band 6, $1.64 \mu \mathrm{m}$; band 7, $2.11 \mu \mathrm{m}$ ) showed some potential for flare detection, as in previous research with Landsat data (Anejionu et al., 2014). Indeed, Elvidge et al. (2013) found that for gas flares (at 1800K) the peak radiant emission is in the shortwave infrared at around $1.6 \mu \mathrm{m}$. However, in the present study the daytime shortwave infrared bands were highly sensitive to other reflective materials including clouds, the built-environment and sands in and around rivers. Similar confounding effects have been found when attempting to use daytime shortwave infrared VIIRS data (band M10, $1.6 \mu \mathrm{m}$ ) for flare detection (Elvidge et al., 2013). Furthermore, gas flares could not be detected from nighttime MODIS bands 6 and 7 as the MODIS reflective bands are turned off during "night mode" scans (MODIS Characterization Support Team, 2012). From the MODIS thermal bands that have previously been used in biomass fire detection only bands 21 and 22 (both $3.96 \mu \mathrm{m}$ ) were useful for flare detection, while band 31 (11.02 $\mu \mathrm{m})$ had no value for flare detection whether acquired during daytime or nighttime. Daytime band

21 and 22 data were responsive to flares but were also sensitive to other hot and reflective surfaces 261 such as urban areas, bare lands and sands due to solar irradiation. Nighttime data were equally responsive to flares but were not subjected to the solar-induced confounding effects. While bands 21 and 22 had similar responses to gas flares, band 21 is known to be noisier with higher quantization error than band 22 (Giglio et al., 2003) and this was evident in the data used for the present study. 
265 The noisiness of band 21 is due to the fact that it has a relatively higher dynamic range than band 22 , 266 to avoid saturation over very hot and large targets and this has made it useful for the detection of 267 biomass fires and volcanoes. However, due to the relatively smaller size of gas flares band 22 is 268 more appropriate. Based on the spectral emission patterns of gas flares elucidated by Elvidge et al. 269 (2013) flares at $1800 \mathrm{~K}$ have a peak radiant emission at around $1.6 \mu \mathrm{m}$ therefore MODIS band 22 $270(3.96 \mu \mathrm{m})$ is on the trailing edge of flare emissions. Using Plank's and Stefan-Bolzmann's Laws, 271 we estimated that for flares at $1800 \mathrm{~K}$ MODIS band 22 would sample approximately $0.63 \%$ of total 272 radiant output, whereas for flares at $1250 \mathrm{~K}$ band 22 would sample $1.01 \%$ of the radiant output. 273 Therefore, MODIS band 22 would become relatively more effective as flare temperature decreases 274 but would be less suitable than a shortwave infrared band for higher temperature flares. However 275 for the practical reasons given above related to solar effects and nighttime MODIS scan configuration techniques described in this study.

Insert Figure 2 Here

Table 1. Spectral and spatial characteristics of the MODIS bands examined in this study.

\begin{tabular}{ccc}
\hline Band & Bandpass $(\boldsymbol{\mu m})$ & Spatial Resolution $(\mathbf{m})$ \\
\hline 6 & $1.628-1.652$ & $500 \mathrm{~m}$ \\
7 & $2.105-2.155$ & $500 \mathrm{~m}$ \\
21 & $3.929-3.989$ & $1000 \mathrm{~m}$ \\
22 & $3.929-3.989$ & $1000 \mathrm{~m}$ \\
31 & $10.780-11.280$ & $1000 \mathrm{~m}$ \\
\hline
\end{tabular}

282 tion, nighttime band 22 data was used for the development of the flare detection and volume estimation techniques described in this study.

\subsection{Development of the MODIS Flare Detection Technique (MODET)}

A method which utilised the radiometric and spatial properties of gas flares was chosen for detecting flares and discriminating them from other features with high thermal emissions. Gas flares are smaller in size than biomass fires, occur at flare stacks and pits permanently fixed to a particular location and are mostly continuously active (SPDC, 2013; Elvidge et al., 2011; Friends of the Earth, 
2005). The continuous combustion of gas is expected to generate a considerable thermal signal that 292 would distinguish fire from non-burning background features. However, given the varying environmental context of flares in the Niger Delta (ranging from offshore, to mangrove swamp and to rainforest areas), we found that a simple threshold method alone was unsuitable for flare detection. We therefore fused a traditional radiometric threshold algorithm with a spatial filtering algorithm capable of identifying gas flares based on differences in radiation between the flare pixels and surrounding pixels. This combination of radiometric and spatial filtering algorithms has been found to be valuable when using thermal imagery for fire detection (Roberts et al., 2005; Roberts and Wooster, 2008). In the present study, the radiometric algorithm applied a threshold to band 22 to identify potential flare sites (see section 3.2.2 below which discusses the selection of the threshold value). The spatial filtering algorithm is an adaptation of earlier methods used in the identification of active fires (Flasse and Ceccato, 1996; Prins and Menzel, 1992) and flares from MODIS imagery (Elvidge et al., 2011). A high pass filter was applied to band 22 in order to identify areas of sharp spatial change in radiance. A $3 \times 3$ kernel was found to be most suitable for highlighting differences between flares and immediate surrounding pixels. The results of the high pass filtering were subsequently reclassified using a threshold to identify potential flare pixels (section 3.2.2 discusses the threshold value). The results of the spatial filtering were then overlaid with the results from the radiometric threshold and potential flare pixels common to both algorithms were taken to be the active flare pixels. The key stages of the MODET are summarised in Figure 3.

Given the spatial resolution of the MODIS imagery $(1 \mathrm{~km})$ it is feasible that within a single pixel or group of pixels identified as flares there may be one or more active flares associated with a 312 flow station. Flares associated with a flow station are typically located within a radius of several 313 hundred metres whereas individual flow stations are located at least several tens of kilometres apart. 314 Therefore, rather than identifying flares (from individual stacks/pits), the MODET actually detects 315 the flaring activity associated with individual flow stations, which we refer to as 'flare sites'. 
High resolution images covering the Niger Delta obtained from Google Earth were visually inspected in order to construct a reference dataset of active flare sites. This approach was adopted as a ground-based survey of flare locations was not feasible at the time of research, due to logistical and security issues associated with fieldwork in the region. Visible fires from gas flares (e.g. centre of Figure 4) were used in conjunction with clearly discernible physical structures such as buildings, pipelines, flare pits and flare stacks to confirm the locations of active flare sites. This method for collecting reference data on flare locations has been employed effectively by previous researchers (Anejionu et al., 2014; Casadio et al., 2012; Elvidge et al, 2009b). The high resolution data covering the study area comprise a mosaic of images acquired over different time periods; as a result no single image or acquisition date was able to provide enough reference flare sites for validation. Hence, the reference dataset of 43 active flare sites was obtained from a range of high resolution images acquired between 2002 and 2007 and this was compared to the outputs of the MODET ap-

331 plied to MODIS imagery for the corresponding years. All active flare sites within the boundaries of 332 the high resolution images were identified by placing a $1 \mathrm{~km}$ resolution vector grid over the imagery and systematically viewing and identifying all flare sites within each grid cell. The boundaries of the high resolution images were used to define the sample areas for validating the MODET, therefore errors of omission and commission could be quantified and the user and producer accuracies 336 for detection computed.

\subsubsection{Identification of optimal thresholds and assessment of detection and spatial accuracy}

To identify the optimal thresholds for the radiometric and spatial filtering algorithms, a range of radiance values were tested. Characteristic background radiance of onshore and offshore environments for the original and spatially filtered band 22 images were used to identify suitable ranges 
343 of thresholds for testing. In turn, thresholds of between 0.5 and $0.7 \mathrm{Wm}^{-2} \mathrm{sr}^{-1} \mu \mathrm{m}^{-1}$ (with an incre344 ment of 0.01 ) were tested for the radiometric algorithm and between 0.2 and $0.5 \mathrm{Wm}^{-2} \mathrm{sr}^{-1} \mu \mathrm{m}^{-1}$ (in345 crement 0.1 ) for the spatial filtering algorithm, and the accuracy of the outputs determined using the 346 validation approach outlined above. Table 2 shows the accuracy statistics for a selection of the best 347 performing combinations of threshold values. The combination of thresholds for the radiometric 348 and spatial algorithms which maximised both user's and producer's accuracy (combination $\mathrm{H}$ in 349 Table 1) was selected for the MODET (Figure 3).

Table 2. Summary statistics of accuracies computed from the different threshold combinations based on a reference

\begin{tabular}{crrrrrrr}
\hline $\begin{array}{c}\text { Combina- } \\
\text { tion }\end{array}$ & $\begin{array}{r}\text { Radiometric } \\
\text { Threshold } \\
\left(\mathrm{Wm}^{-2} \mathrm{sr}^{-1} \mu \mathrm{m}^{-1}\right)\end{array}$ & $\begin{array}{r}\text { Spatial } \\
\text { Threshold } \\
\left(\mathrm{Wm}^{-2} \mathrm{sr}^{-1} \mu \mathrm{m}^{-1}\right)\end{array}$ & $\begin{array}{r}\text { Total } \\
\text { Detections }\end{array}$ & $\begin{array}{r}\text { Flares } \\
\text { omitted }\end{array}$ & $\begin{array}{r}\text { Detections } \\
\text { Confirmed }\end{array}$ & $\begin{array}{r}\text { Producer's } \\
\text { accuracy }\end{array}$ & $\begin{array}{r}\text { User's } \\
\text { Accuracy }\end{array}$ \\
\hline $\mathrm{A}$ & 0.66 & 0.4 & 35 & 10 & 35 & 76.7 & 100.0 \\
$\mathrm{~B}$ & 0.645 & 0.4 & 35 & 10 & 35 & 76.7 & 100.0 \\
$\mathrm{C}$ & 0.6 & 0.4 & 36 & 9 & 36 & 79.1 & 100.0 \\
$\mathrm{D}$ & 0.56 & 0.4 & 40 & 6 & 40 & 86.1 & 100.0 \\
$\mathrm{E}$ & 0.6 & 0.2 & 43 & 4 & 41 & 90.7 & 95.4 \\
$\mathrm{~F}$ & 0.6 & 0.3 & 42 & 5 & 41 & 88.4 & 97.6 \\
$\mathrm{G}$ & 0.6 & 0.5 & 40 & 6 & 40 & 86.1 & 100.0 \\
$\mathrm{H}$ & $\mathbf{0 . 5 6}$ & $\mathbf{0 . 3}$ & $\mathbf{4 3}$ & $\mathbf{4}$ & $\mathbf{4 3}$ & $\mathbf{9 0 . 7}$ & $\mathbf{1 0 0 . 0}$ \\
\hline
\end{tabular}

To compute the spatial accuracy of the MODET, the coordinates of the centroids of 20 flare sites detected by the technique were compared with the coordinates of corresponding reference flares derived from the high resolution imagery (Table 3). Offsets in latitude and longitude between the MODET detection and the reference flare locations were used to compute the root mean square error (RMSE) for each flare site and the mean RMSE $(844 \mathrm{~m})$ was used as a measure of the spatial accuracy of the MODET.

Table 3. Details of the MODET detections and reference flare locations used to compute the spatial 362 accuracy of the MODET

\begin{tabular}{|c|c|c|c|c|c|}
\hline \multicolumn{2}{|c|}{ MODET Detections } & \multirow[b]{2}{*}{ Flare Site ID } & \multicolumn{2}{|c|}{ Reference flares } & \multirow[b]{2}{*}{$\operatorname{RMSE}(\mathrm{m})$} \\
\hline Long $\left({ }^{\circ}\right)$ & Lat $\left({ }^{\circ}\right)$ & & Long $\left({ }^{\circ}\right)$ & Lat $\left({ }^{\circ}\right)$ & \\
\hline 6.521486 & 5.659878 & MODET 11 & 6.517196 & 5.659283 & 480 \\
\hline 6.708013 & 5.456133 & MODET 22 & 6.694344 & 5.458499 & 1539 \\
\hline 6.662598 & 5.387761 & MODET 27 & 6.657883 & 5.386097 & 555 \\
\hline
\end{tabular}




\begin{tabular}{rllrrr}
\hline 6.616185 & 5.239537 & MODET 31 & 6.628775 & 5.236312 & 1442 \\
6.493413 & 5.191626 & MODET 33 & 6.491294 & 5.197543 & 697 \\
6.506888 & 5.097302 & MODET 35 & 6.506823 & 5.099702 & 266 \\
6.364653 & 5.026933 & MODET 37 & 6.358577 & 5.024974 & 708 \\
6.379626 & 4.882203 & MODET 47 & 6.372342 & 4.885274 & 877 \\
6.08198 & 4.657122 & MODET 53 & 6.07764 & 4.661282 & 667 \\
7.06385 & 4.652631 & MODET 55 & 7.060293 & 4.652185 & 397 \\
6.272682 & 4.628248 & MODET 56 & 6.26458 & 4.628168 & 899 \\
6.673079 & 4.544832 & MODET 60 & 6.664416 & 4.549694 & 1102 \\
7.009052 & 4.552018 & MODET 61 & 7.003554 & 4.55646 & 784 \\
8.016076 & 4.547077 & MODET 62 & 8.010454 & 4.552057 & 833 \\
7.049092 & 4.544832 & MODET 63 & 7.045435 & 4.553114 & 1004 \\
6.634151 & 4.523871 & MODET 64 & 6.632621 & 4.526412 & 329 \\
5.280867 & 5.668245 & MODET 123 & 5.275077 & 5.673164 & 843 \\
6.718174 & 4.554332 & MODET 148 & 6.710037 & 4.55965 & 1078 \\
5.133817 & 5.84871 & MODET 238 & 5.133365 & 5.860184 & 1274 \\
5.17438 & 5.614197 & MODET 173 & 5.173002 & 5.624002 & 1099 \\
\hline Note: Mean RMSE $=844 m$ & & & &
\end{tabular}

364

\subsubsection{Application of the MODET}

The MODET was subsequently applied to the bi-monthly (December-January) temporal composites covering the 2000 to 2014 study period. The number of times each flare site was detected was recorded with sites that were detected only once over the fifteen sampling occasions removed as false detections. This is because once flow stations are constructed and flares become active they burn continuously over their operational period which is typically in decadal time scale (SPDC, 2013, Onwuka, 2003). Therefore gas flares are highly unlikely to occur on only a single sampling occasion, whereas biomass fires, or other high radiance features are much more ephemeral. Previous studies have utilised a similar persistence approach in discriminating flares from false identifications (Casadio et al. 2012a, 2012b) or to normalise the impact of background noise on flare detections (Elvidge et al., 2009a). Since we do not have data from subsequent years to confirm if the flares detected in 2013/14 were persistent, we incorporated them into the output, on the basis that their detections satisfied the MODET procedure. The flares identified within the study period were used to obtain a flaring history detailing the spatial and temporal variations in the distribution of active flares in the region. The Nigerian political map was used to allocate the detected flares to the 
different states in the region. As the map did not delineate offshore state boundaries, offshore flares were objectively allocated to the state with the nearest onshore boundary by Euclidean distance. The onshore and offshore flaring was then used to calculate the overall activity for each state, on each sampling occasion.

\subsection{Development of the MODIS Flare Volume Estimation Technique (MOVET)}

The MOVET is based on the concept that the volume of gas flared at each flow station for any given time period (i.e. the combustion rate) would determine the intensity of fire at that location, and by extension the magnitude of the spectral radiance emitted at the location, captured by the MODIS sensor. We therefore set out to establish a method that would optimally harness the information contained in the radiance at the flare sites (flare pixels) and surrounding environment (background pixels), to estimate the volume of gas flared. Having identified the locations of flare sites using the MODET, MODIS band 22 was analysed further to derive a statistical relationship between the spectral radiance of flare sites and the volume of gas flared. Due to the difficulty in accessing official records of oil and gas related information in Nigeria (which gave rise to the present research on alternative information sources on flaring), it was only possible to match detections from the MODET with records of the volume of gas flared at 29 sample flow stations across the region in December 2004 (data sourced from Nigerian National Petroleum Corporation). Consequently, the band 22 temporal composite image from December 2004 was used together with the flare volume records in order to develop the MOVET.

A number of different approaches were explored in order to develop the MOVET. The first stage was to apply a series of different methods for extracting pixel values from the vicinity of detected flare sites, and the second was to use a number of different ways to derive radiometric variables from the extracted pixels. The combination of extraction approach and radiometric variables that produced the strongest correlation with the flare volume records was used for the MOVET. The pixel extraction approaches that were tested were: (i) use of individual or groups of flare pixels at 
each flare site; (ii) identification of a centroid location for individual or groups of flare pixels at 407 each flare site then construction of a circle of different sizes $(1,2,3 \mathrm{~km})$ around this point and extraction of all pixels which intersected with the circle (to incorporate flare and background pixels); (iii) use of a buffer of 1 to 3 pixels around each individual or group of flare pixels and extraction of all flare and background pixels within this region. The radiometric variables derived from the 411 groups of pixels extracted in the previous stage were: (i) statistical parameters (minimum, maxi412 mum, range, sum, mean and standard deviation); (ii) combinations of the statistical parameters such 413 as the product of mean and maximum, standard deviation and sum, and the difference between the 414 maximum and minimum. These combinations of statistical parameters enabled quantification of 415 various relationships between flare and background radiance values, for example, the difference be416 tween the maximum and minimum measured the radiance increase above background generated by 417 flares; (iii) calculation of the Fire Radiative Power based on fire and background pixel radiances 418 (Wooster et al., 2003); (iv) calculation of the magnitude of slope in radiance between flare pixels 419 and background pixels expressed as a mean value for each group of pixels considered. The optimal 420 combination of pixel extraction approach and radiometric variables was used as the basis as $421 \quad$ MOVET as follows.

The MOVET is based on the combined use of the total radiation intensity at the flare site and 423 a measure of the localised influence of the flares over their surrounding environment. It is thus a 424 hybrid absolute and contextual approach for estimating flare volume which incorporates radiance 425 values of flare pixels and surrounding pixels. A buffer of 1 pixel around flare pixels (i.e. in the case 426 of an individual flare pixel constitutes a $3 \times 3$ pixel window with the flare at the centre) was found to 427 be optimal for capturing the radiometric zone of influence of flares and some areas of background 428 that were unaffected by flares. The 1 pixel buffer accommodated the variability and effects of gas 429 flares in the different environmental contexts. Regression analyses performed on reported flare vol430 ume and radiance statistics for the 29 sample flare sites demonstrated that the optimal predictor of 
flare volume was a combination of the sum and standard deviation of radiance values of the extracted pixels at flare sites $\left(\mathrm{R}^{2}=0.77, \mathrm{p}<0.01\right.$; see Figure 5) which was used as the basis of the MOVET:

$$
V=375\left(\Sigma r^{2} . \sigma r\right)+6230
$$

$$
\text { where } V=\text { flare volume (Million Cubic Metres); }
$$

$$
\Sigma r=\text { sum of radiance }\left(\mathrm{Wm}^{-2} \mathrm{sr}^{-1} \mu \mathrm{m}^{-1}\right)
$$

$\sigma r=$ standard deviation of radiance $\left(\mathrm{Wm}^{-2} \mathrm{sr}^{-1} \mu \mathrm{m}^{-1}\right)$.

Here $\Sigma r^{2}$ quantifies the absolute intensity of emissions of the flare site while $\sigma r$ provides a measure of the local variation between the radiation from flares and their immediate surroundings. Across the Niger Delta flares are positioned in a variety of environmental contexts (mangrove swamps, rainforest, offshore) with varying background radiance, therefore a given volume of combusted gas may lead to different total radiance emissions from the flare site depending on the context. Therefore, incorporation of $\sigma r$ into the MOVET model provides the contextual information that effectively normalises the total radiation from each flaring site by accounting for varying local conditions.

\section{Insert Figure 5 here}

The predictive power of the MOVET model was tested using the leave-one-out cross validation method (Arlot and Celisse, 2010) based on the sample of 29 flare sites. This revealed a RMSE of 0.007 Billion Cubic Metres (BCM) per month (28\% of the mean), equating to an annual estimation error of 0.084BCM for individual flare sites.

\subsection{Estimating volumetric rate of gas flaring in the Niger Delta (2000 - 2013)}

The MOVET was applied to each temporal composite MODIS band 22 image for January and December of each sample year in order to estimate the volume of gas flared at all identified flare sites. In order to estimate the annual total volume of gas flared at each site, we needed to derive estimates of flaring volume in each month of the year. We observed from the available summary of monthly volumes reported for 2005 (the only year for which monthly data was available) that 
monthly variation in flaring in the region was minimal with a coefficient of variation of $9.6 \%$ and no systematic seasonal fluctuation. This indicated that it was acceptable to quantify monthly flaring volumes based on the January and December estimates from MOVET. Therefore, for each flare site, the volume estimates derived from the January and December monthly temporal composites in the same calendar year were interpolated linearly to estimate volumes for all months of that year. The twelve monthly volume estimates were then summed in order to calculate an annual volume of gas combusted for each flare site. This process was repeated across the MODIS archive in order to derive an annual estimate for volume of gas combusted at each flare site for each year from 2000 to 2013. The volume combusted at each site was summed over the entire study period and totals were calculated for each state in the Niger Delta and the whole region. Uncertainty in the flare volume estimates was expressed using the upper and lower 99\% confidence intervals for the slope and intercept derived from the calibration of the MOVET (see section 3.3) for individual flare sites, scaled to annual estimates for states and the study site, as appropriate.

\subsection{Results}

\subsection{Spatial and temporal distribution of flare sites in the Niger Delta}

The MODET detected 271 flare sites (190 onshore and 81 offshore) from 2000 to 2014. The spatial distribution of the flares across the states of the Niger Delta is shown in Figure 6. The figure also illustrates the number of times each of the flare sites was detected within the study period based on an annual sampling interval, which is indicative of the duration of activity at each site. For clarity, the number of detections recorded in Figure 6 do not represent detections in individual MODIS images, rather they represent the number of detections in each of the bi-monthly temporal composites from each sample year. This is why the maximum number of detections is 15 , where an individual flare has been detected in all of the 15 bi-monthly temporal composites that were analysed between 2000 and 2014. 
The number of flare sites identified per state is shown in Table 4. Rivers State had the highest 485 proportion of flare sites in the region over the study period (27\%), closely followed by Delta State 486 (26\%). Whilst Akwa Ibom State had only 13\% of flares sites, it possessed the greatest proportion of 487 offshore flare sites in the region, with $37 \%$ of all offshore flare sites in the Niger Delta being locat488 ed in this state.

490

Table 4. Distribution of flare sites across the Niger Delta States (2000-2014)

\begin{tabular}{lccc}
\hline State & Onshore flare sites & Offshore flare sites & All flare sites \\
\hline Rivers & 56 & 16 & 72 \\
Delta & 51 & 19 & 70 \\
Bayelsa & 41 & 12 & 53 \\
Akwa Ibom & 6 & 30 & 36 \\
Edo & 19 & 0 & 19 \\
Ondo & 5 & 4 & 9 \\
Imo & 11 & 0 & 11 \\
Abia & 1 & 0 & 1 \\
Total & $\mathbf{1 9 0}$ & $\mathbf{8 1}$ & $\mathbf{2 7 1}$ \\
\hline
\end{tabular}

The temporal trajectory of flaring activity across the Niger Delta is shown in Figure 7, which indicates a downward trend from the peak in 2000 to 2014. Each sampling interval indicates a maintenance or decrease in flaring activity, with the largest decreases from 2000 to 2001 and 2013 to 2014 with the only increase in activity from 2010 to 2011 .

Insert Figure 7 here

\subsection{Spatial and temporal distribution of the volume of gas flared in the Niger Delta}

The outputs of the MOVET suggest that there was a wide variation in the annual volume of gas flared at individual flow stations (Table 5). This table shows the specific flare sites which have the smallest and largest volumes of gas combustion within each year, along with the annual mean and standard deviation. The maximum volume for an individual flare site was 4.60BCM, which was recorded in 2005 in Rivers State (MODET 58), and the minimum volume of 0.0363BCM was recorded in Imo State (MODET 224) in 2009. From the peak at 2005, there was a general reduction in the mean volume of gas combusted at individual flare sites and a decrease in the variability of flared volume. 
506 Table 5. Summary of annual variations in volume of gas estimated for individual flare sites. The uncertainties are computed based on the upper and lower con-

\begin{tabular}{|c|c|c|c|c|c|c|c|c|c|c|c|c|c|}
\hline Year & $\begin{array}{c}\text { Min } \\
(\mathrm{BCM})\end{array}$ & $\begin{array}{c}\text { Uncertainty } \\
( \pm)\end{array}$ & Flare ID & State & Location & $\begin{array}{c}\text { Max } \\
\text { (BCM) }\end{array}$ & $\begin{array}{c}\text { Uncertainty } \\
( \pm)\end{array}$ & Flare ID & State & Location & $\begin{array}{c}\text { Mean } \\
(\text { BCM) }\end{array}$ & $\begin{array}{c}\text { Uncertainty } \\
( \pm)\end{array}$ & $\begin{array}{c}\text { Std } \\
\text { DEV }\end{array}$ \\
\hline 2000 & 0.0370 & 0.013 & MFDT 52 & Rivers & Onshore & 1.596 & 0.463 & MFDT 58 & Rivers & Onshore & 0.192 & 0.057 & 0.256 \\
\hline 2001 & 0.0369 & 0.012 & MFDT 268 & Edo & Onshore & 2.383 & 0.691 & MFDT 58 & Rivers & Onshore & 0.209 & 0.062 & 0.325 \\
\hline 2002 & 0.0372 & 0.013 & MFDT 339 & Delta & Onshore & 2.039 & 0.592 & MFDT 58 & Rivers & Onshore & 0.200 & 0.060 & 0.296 \\
\hline 2003 & 0.0369 & 0.012 & MFDT 98 & Rivers & Onshore & 3.013 & 0.874 & MFDT 58 & Rivers & Onshore & 0.221 & 0.066 & 0.350 \\
\hline 2004 & 0.0364 & 0.012 & MFDT 367 & Bayelsa & Onshore & 3.792 & 1.099 & MFDT 58 & Rivers & Onshore & 0.225 & 0.067 & 0.414 \\
\hline 2005 & 0.0374 & 0.013 & MFDT 217 & Rivers & Onshore & 4.602 & 1.333 & MFDT 58 & Rivers & Onshore & 0.265 & 0.078 & 0.501 \\
\hline 2006 & 0.0372 & 0.013 & MFDT 332 & Edo & Onshore & 3.606 & 1.045 & MFDT 58 & Rivers & Onshore & 0.249 & 0.074 & 0.448 \\
\hline 2007 & 0.0371 & 0.013 & MFDT 339 & Delta & Onshore & 2.860 & 0.829 & MFDT 61 & Rivers & Onshore & 0.249 & 0.074 & 0.416 \\
\hline 2008 & 0.0372 & 0.013 & MFDT 114 & Ondo & Onshore & 1.941 & 0.563 & MFDT 22 & Rivers & Onshore & 0.192 & 0.057 & 0.314 \\
\hline 2009 & 0.0363 & 0.012 & MFDT 224 & Imo & Onshore & 1.022 & 0.297 & MFDT 75 & Rivers & Onshore & 0.161 & 0.048 & 0.175 \\
\hline 2010 & 0.0372 & 0.013 & MFDT 2 & Edo & Onshore & 1.123 & 0.327 & MFDT 75 & Rivers & Onshore & 0.142 & 0.043 & 0.167 \\
\hline 2011 & 0.0373 & 0.013 & MFDT 332 & Edo & Offshore & 2.043 & 0.593 & MFDT 231 & Akwa Ibom & Offshore & 0.159 & 0.048 & 0.255 \\
\hline 2012 & 0.0369 & 0.012 & MFDT 106 & Rivers & Onshore & 2.253 & 0.654 & MFDT 231 & Akwa Ibom & Offshore & 0.157 & 0.047 & 0.269 \\
\hline 2013 & 0.0370 & 0.013 & MFDT 227 & Akwa Ibom & Offshore & 0.475 & 0.139 & MFDT 87 & Rivers & Offshore & 0.100 & 0.031 & 0.094 \\
\hline
\end{tabular}


Figure 8 shows the spatial distribution of individual flare sites and the total volume of gas

524 combusted at each site over the study period. Figure 8 also shows the total volume of gas flared 525 within each state over the study period. The results demonstrate that the volume of gas flared at individual sites varied by over two orders of magnitude, as did the volume of gas flared across the states. Rivers State flared the greatest volume of gas (135BCM) over the study period, followed by Bayelsa State (71BCM). Figure 9 summarises variations in flaring activities between states in the region over the study period. Most states showed an initial phase of increasing activity followed by a general decrease, although the timing of these phases differs between states and some states do not show this pattern of activity. Figure 9 also shows that there are wide variations between states in the contributions of onshore and onshore flaring, and in those states where there is a mixture there are differing trajectories of onshore and offshore activity with offshore generally becoming more prevalent over time.

mum (36BCM) in 2005 before subsequently declining from 2006 to 2009 . There was however, a brief increase in activity from 2010 to 2011, followed by another period of decline to the present levels. These annual volume estimates derived from the MOVET show a reasonably close correspondence with the trend of the reported volumes of gas flared for the Niger Delta published by the ures. Official reports are not available for 2013, but the MOVET indicated a substantial reduction in

Figure 10 shows the trajectory of annual volumes of gas flared across the whole Niger Delta region over the study period. This reveals that flaring activity increased initially, reaching a maxiNNPC (2012) (also shown in Figure 10). There are some discrepancies, notably at the middle of the study period where the MOVET estimates showed much greater variability than the reported figflaring volume in the final stage of the study period. The MOVET outputs produced an estimate that a total of 350 BCM of gas was flared in the region from March 2000 to January 2014. 


\subsection{Discussion}

The location of flare sites detected by the MODET varied considerably at the state level, with some states such as Rivers and Delta having substantially more terrestrial flare sites than offshore, whilst others such as Akwa Ibom had the inverse. However, the regional distribution of the flare sites shows that there are more flare sites in the terrestrial environment than the marine environment. This explicit level of variation detected using MODIS data is important as it may be used to isolate and specifically study the varying impacts of flare sites for any particular area. For example flaring in Akwa Ibom State is expected to have greater impact on the marine environment than the terrestrial environment, based on the distribution of the flare sites shown in Figure 6. On the other hand,

561 the terrestrial environment of Rivers State will be the most impacted. Furthermore, the spatial distribution of the flares and the number of times they were detected over the study period showed various clusters of flaring activity. This suggests that the environmental impacts of flaring could be highly heterogeneous, with extreme values in certain locations.

The MODET revealed an overall reduction in the number of active flare sites between 2000 and 2014 (Figure 5). This may have been as a result of the decommissioning of some flare sites due to the commencement of full operations at the Nigerian Liquefied Natural Gas facility at Bonny Island in late 1999 and subsequent commissioning of additional gas liquefaction trains from 2002, which led to increased commercial utilisation of gases associated with extracted crude oil (NLNG, 2013).

570 The noticeable downward trend in the number of flare sites between 2006 and 2009 corresponds to 571 the period when oil and gas production in the region was severely disrupted by the Niger Delta militants (Paki and Ebienfa, 2011; Punch Newspaper, 2009). Also towards the end of 2005 gas plants were commissioned at Kwale/Okpai by Nigeria Agip Oil Company, and Okoloma by the Shell Petroleum Development Company (SPDC, 2011), both of which became fully operational from 2006. 
(National Petroleum Investment Management Services, 2010). The brief increase in numbers of flare sites between 2010 and 2011, marked the return of relative peace in the region at the commencement of the Amnesty programme by the Federal Government of Nigeria (BBC, 2009), which appears to have enabled a short period of increased oil and gas production. Since 2011 there has been a steady decline in the number of active flare sites through to present. During this period there has not been any significant unrest in the region that could disrupt oil and gas production, hence the decrease in numbers of flare suggests a decline in the use of flaring to dispose of gas. This may be a consequence of the Soku liquefied natural gas feeder plant, which supplies $40 \%$ of the 22 million tonnes of gas per annum (30BCM) to the liquefaction facility at Bonny Island, returning to full operation towards the end of 2009 (Fineren, 2009). There has also been installation of associated gas gathering infrastructure at various oilfields in the Niger Delta by the oil companies, such as those at 587 Forcados-Yokri and Southern Swamps (SPDC, 2013), which has reduced the requirement for flar588 eradication of gas flaring in the region. However, further monitoring of the situation using the MODET is required in order to confirm this trend in subsequent years.

The MOVET showed that there was considerably variability between individual flare sites in the volume of gas flared per annum and this is a reflection of the varying quantities of gas produced at the different flow stations. Gas produced at flow stations varies due to the commissioning or decomissioning of oil wells that are feeding into a station, changes in the rate of oil and gas production from individual wells and inter and intra well variation in the ratio of associated gas to oil during the production cycle (International Association of Oil and Gas Producers, 2000). Interestingly, the minimum volume combusted by an individual flare site was recorded in 2009 which coincided with the peak in social unrest in the region, which drastically disrupted oil production activities. However, of greater significance is the systematic decrease in maximum and mean volumes com- 
combustion has also decreased which may be a result of reduced production from the wells contributing to flow stations and/or implementation of alternative strategies for dealing with associated gas.

The state-level trajectories of the volumes of gas combusted (Figure 7) illustrated the specific contributions of onshore and offshore flares to the total for each state as well as annual variations in those contributions. We found that prior to the recent decline in flaring activity in 2013, in states such as Rivers (which has the highest flaring volume among the states) and Akwa Ibom there was a noticeable decline in onshore flaring volume, while the offshore volume gradually increased over the same period. This suggests intensified offshore oil exploitation and decreasing onshore activities in these states, which could be as a result of discoveries of new offshore oilfields such as Bonga, Oyo, Ofon, Usan and Egina. Delta State however, shows a recent increase in onshore flaring volume after an initial decline and steadily decreasing offshore flaring activity. In addition there is a general decline in onshore and offshore flaring volume in Bayelsa State. It was also found that although Delta State had a greater number of active flare sites than Akwa Ibom or Bayelsa states, greater volumes of gas were combusted in Akwa Ibom (71BCM over the study period) and Bayelsa State (61BCM) than in Delta State (49BCM). This could be due to a lower gas to oil ratio in the oilfields in Delta State, or because a larger proportion of the gas produced from Delta State is being utilized at recycling locations such as the Forcados-Yokri and Southern Swamp AGG, as well as the Kwale/Okpai gas plant, which are all located in Delta State. As these observations demonstrate, a significant advantage of the MOVET is the ability to provide information with sufficient spatial precision to permit analysis of oil exploitation strategies in different states and, potentially, detailed evaluation of the impacts of gas flaring. This level of information has not been previously explored in flare-related research using remote sensing which has tended to focus on national or global scales (Elvidge et al., 2009a, 2009b, Casadio et al., 2012), whereas the emphasis with MOVET is at the level of the individual flow station. 
The regional trajectory of the volume of gas combusted (Figure 8) showed a general increase

628 in the first half of the study period corresponding with increasing oil production, followed by a decrease in the second half in response to reduced oil production due to social disruption in the region, in conjunction with the introduction of measures to reduce flaring such as liquefaction of gas. The 631 regional trajectory also indicated that the infrastructure for reducing gas flaring was already in place 632 by the end of the period of unrest in 2009 , because although oil production returned to levels expe633 rienced before the period of unrest, the volume of gas flared continued to decrease. There is an 634 overall tendency for the estimates for gas flaring from MOVET to be higher than the reported val635 ues, with a notable discrepancy during the period of peak flaring in 2005-2006. This highlights the 636 importance of having an alternative means of obtaining information on gas flaring that is independ637 ent of official sources which rely on data provided by the oil companies. Our method determined 638 that a considerable volume of natural gas (350 BCM) has been flared in the region over the study 639 period; this has an energy value of $3.71 \times 10^{9} \mathrm{MWh}$ which, by way of comparison, is approximately 64010 times the annual electrical power consumption of the United Kingdom. Assuming that $184 \mathrm{~kg}$ of 641 carbon dioxide is produced per MWh of natural gas (DEFRA, 2013), the gas flared in the Niger 642 Delta over the study period has resulted in $682.64 \mathrm{Mt}$ of carbon dioxide being released to the atmos643 phere, suggesting a significant contribution of greenhouse gasses and other pollutants during this 644 period.

Owing to the low spatial resolution of MODIS data, the spatial accuracy of the MODET was found to be $844 \mathrm{~m}$, which is very much lower than the $24 \mathrm{~m}$ spatial accuracy obtained from the Landsat Flare Detection Method (Anejionu et al., 2014). However, for regional and state-based studies 648 such as that undertaken here, the MODET appears adequate. Indeed, the distribution of active flare 649 sites in the Niger Delta detected with MODIS data closely corresponds with that obtained from Landsat (Anejionu et al., 2014). The low spatial resolution of MODIS data may also have resulted 651 in the non detection of low intensity flares, leading to the under-detection of $9.3 \%$ based on the cal652 culated producer's accuracy of the MODET. Nevertheless, the spatial resolution of the data did not 
653

restrict the user's accuracy. Cloud cover was a limiting factor encountered in the course of this research. As with many areas of the world the Niger Delta is heavily cloud covered and this limits the sampling opportunities for passive optical remote sensing. However, the frequent revisit times of the Terra and Aqua platforms meant that it was possible to construct cloud-free temporal composite images which formed the basis of the MODET and MOVET. The temporal sampling was limited to certain months of the year and it was not possible to characterise intra-annual variations in gas flaring activity, but the temporal sampling was sufficient for monitoring the longer-term inter-annual trajectories in flaring. While the annual estimates of flaring volume from MOVET were based on the reasonable assumption that intra-annual variations are minimal at active flare sites, it is likely that estimates could be improved if more frequent sampling was possible. In this context, the combination of information derived from MODIS together with that from other passive and active satellite systems, may help to reduce the impacts of cloud cover and thereby increase the temporal sampling opportunities. For instance, it has been shown that SOUMI VIIRS data is valuable for flare detection (Elvidge et al., 2013). Furthermore, pre-launch algorithm development has demonstrated the potential of the forthcoming Sea and Land Surface Temperature Radiometer on Sentinel-3 in gas flare detection (Wooster et al., 2012). These systems are expected to play active role in the future monitoring of gas flaring activities around the world.

\section{$672 \quad 6.0$ Conclusion}


This research has demonstrated the utility of MODIS data for detecting individual gas flare

674 sites and estimating the volume of gas combusted at these sites. Two MODIS-based techniques, MODET and MOVET were developed which were capable of providing alternative sources of information on gas flaring activity. The techniques were applied to the Niger Delta region and the outputs provided detailed information on the spatial and temporal variability of gas flaring activity in the region for the past 14 years.

The methods developed in this research provide an objective means of monitoring gas flaring activity which is particularly important in areas such as the Niger Delta, where investigations of gas flaring have previously been hampered by restricted access to official information on flares. Using freely-available MODIS data, the MODET and MOVET are consistent across different oil fields; they are timely and reduce delays associated with traditional methods of acquiring flaring data; and the data is independent of particular companies or authorities. In principle, with the MODET and MOVET flaring can be investigated at spatial scales ranging from that of the individual flare site up to global level and across the time scale covered by the MODIS archive. However, it is now important that the robustness and transferability of the techniques is evaluated in other oilproducing regions of the world. This will enable the methods to make a key contribution to monitoring the compliance of countries to the Global Gas Flaring Reduction initiative and for modelling the health and environmental impacts of flaring.

\section{Acknowledgements}

693 We wish to acknowledge the Surveyors Council of Nigeria (SURCON), who partly supported the initial stages of this project with a research grant, the Department of Geoinformatics and Surveying, University of Nigeria Enugu Campus, for the provision of the political map used in this research and the Petroleum Technology Development Fund (PTDF Nigeria) who sustained the later stages of this research via a scholarship. Thanks also to Lancaster University for the award of William Ritch- 
MODIS data used in the research.

\section{References}

Abdulkareem, A. S. (2005a). Evaluation of ground level concentration of pollutant due to gas flaring by computer simulation: A case study of Niger - Delta area of Nigeria. http://lejpt.academicdirect.org/A06/29_42.htm (accessed 14th November, 2013).

Abdulkareem, A.S. Afolabi, A.S. Abdulfatai, J., Uthman, H., \& Odigure, J.O., (2012). Oil Exploration and Climate Change: A case study of heat radiation from gas flaring in the Niger Delta area of Nigeria. InTech, 1-27.

Arlot, S. \& Celisse, A. (2010). A survey of cross-validation procedures for model selection. Statistics Surveys, 4, 40-79.

Anomohanran, O. (2012). Thermal effect of gas flaring at Ebedei area of Delta State, Nigeria. Pacific Journal of Science and Technology, 13(2):555-560.

African Technology Policy Studies Network (ATPS). (2013). Multi-temporal threshold algorithm in forest fire detection using MSG satellite: The case of Zimbabwe. ATPS Working Paper No. 76.

Anejionu C.D.O., Blackburn, G.A., \& Whyatt, J.D. (2014). Satellite survey of gas flares: development and application of a Landsat-based technique in the Niger Delta. International Journal of Remote Sensing, 35(5), 1900-1925.

BBC NEWS, 2009, Nigeria offers militants amnesty. http://news.bbc.co.uk/1/hi/8118314.stm (accessed on 17th April, 2012).

Casadio, S., Arino, O., \& Serpe, D. (2012a). Gas flaring monitoring from space using the ATSR instrument series. Remote Sensing of Environment, 116, 239-249.

Casadio. S., Arino, O., \& Minchella, A. (2012b). Use of ATSR and SAR measurements for the monitoring and characterisation of nighttime gas flaring from off-shore platforms: The North Sea test case. Remote Sensing of Environment, 123, 175-186.

Casadio, S., \& Arino, O. (2009). A new algorithm for the ATSR World Fire Atlas. Proceedings EARSEL 2009 Symposium. http://due.esrin.esa.int/wfa/Casadio_Arino_Earsel_2009.pdf. (accessed on 23rd July, 2012).

Casanova, J.L., Calle, A., Romo, A., \& Sanz, J. (2005). Forest fire detection and monitoring by means of an integrated MODIS-MSG system. Remote Sensing Laboratory of University of Valladolid. http://www.iki.rssi.ru/earth/articles/sec9 12.pdf (accessed on 12th February, 2011)

Croft, T.A. 1978. Nighttime images of the earth from space. Scientific American, 239, 68-79.

Csiszar, I., Schroeder, W., Giglio, L., Justice, C.O., \& Ellicott, E. (2012). Establishing active fire data continuity between Aqua MODIS and SUOMI NPP VIIRS. http://www.star.nesdis.noaa.gov/jpss/documents/meetings/2012/AMS_NewOrleans_2012/Oral/2012 AMS_Csiszar_Fire_V1.pdf (accessed on 3rd July, 2014).

Department of Environment Food and Rural Affairs (DEFRA) (2013). 2013 Government GHG Conversion Factors for Company Reporting: Methodology Paper for Emission Factors. https://www.gov.uk/government/uploads/system/uploads/attachment_data/file/224437/pb13988emission-factor-methodology-130719.pdf (Accessed on 9th March, 2014).

Dozier, J. (1981). A method for satellite identification of surface temperature fields of subpixel resolution, Remote Sensing of Environment, 11, 221-229.

Dung, E.J., Bombom, L.S., \& Agusomu, T.D. (2008). The effects of gas flaring on crops in the Niger Delta, Nigeria. GeoJournal, 73, 297-305.

Elvidge, C.D., Baugh, K.E., Tuttle, B.T., Howard, A.T., Pack, D.W., Milesi, C., \& Erwin, E.H. (2007). A twelve year record of national and global gas flaring volumes estimated using satellite data. Final report 
to the World Bank. http://siteresources.worldbank.org/INTGGFR/Resources/DMSP_flares_ 20070530_b-sm.pdf (accessed on 11th October, 2009).

Elvidge, C.D., Ziskin, D., Baugh, K.E., Tuttle, B.T., Ghosh, T., Pack, D.W., Erwin, E.H. \& Zhizhin, M. (2009a). A fifteen year record of global natural gas flaring derived from satellite data. Energies, 2, 595-622.

Elvidge, C.D., Baugh, K.E., Tuttle, B.T., Ziskin, D., Ghosh, T., Zhizhin, M., \& Pack, D.W. (2009b). Improving satellite data estimation of gas flaring volumes. Year two final report to the GGFR. http://www.ngdc.noaa.gov/dmsp/interest/flare_docs/NGDC_flaring_report_20090817.pdf. (accessed on 1st February 2011).

Elvidge, C.D., Baugh, K.E., Ziskin, D., Anderson, S., \& Ghosh, T. (2011). Estimation of gas flaring volumes using NASA MODIS Fire detection products. Report presented to NASA.

Elvidge, C.D., Zhizhin, M., Hsu, F., and Baugh, K.E. (2013). VIIRS Nightfire: Satellite Pyrometry at Night. Remote Sensing, 5, 4423-4449.

Fineren, D. (2009). Nigeria LNG sees stable Soku gas feed by 2010-exec. Reuters. http://uk.reuters.com/article/2009/12/02/nigeria-lng-soku-idUSGEE5B11YU20091202 (Accessed on 9th March, 2014).

Flasse, S.P., \& Ceccato, P.S. (1996). A contextual algorithm for AVHRR fire detection. International Journal of Remote Sensing 17, 419 - 424.

Friends of the Earth. (2005). Communities sue Shell to stop Nigerian gas flaring. Archived press release. http://www.foe.co.uk/resource/press_releases/communities_sue_shell_to_s_20062005.html (accessed on 5th October, 2009).

Friends of the Earth. (2004). Shell oil and gas flaring in Nigeria. http://www.foe.co.uk/resource/images/shell_nigeria_2006/slides/EG_Gas\%20flare\%20Kolo\%20Creek $\% 20$ shot\%201.html (accessed on 5th October, 2009).

Gallegos, S., Ryan, R.E., Baud, R., \& Bloemker, J.M. (2007). MODIS products to improve the monitoring of gas flaring from offshore oil and gas facilities. Final Report to NASA.

Giglio, L., Descloitres, J., Justice, C.O., \& Kaufman, Y.J. (2003). An enhanced contextual fire detection algorithm for MODIS. Remote Sensing of Environment 8, 273-282.

Giglio, L., Schroeder, W., Boschetti, L., Roy, D., Justice, C. (2014). Collection 6 MODIS Fire Products. Presented at MODIS Science Team Meeting at the Sheraton Columbia Town Center in Columbia, Maryland (April 29 - May 1).

Holben, B.N. (1986). Characteristics of maximum-value composite images from temporal AVHRR data. International Journal of Remote Sensing, 7, 1417-1434.

Huete, A., Didan, K., Miura, T., Rodriguez, E., Gao, X., \& Ferreira, L. (2002). Overview of the radiometric and biophysical performance of the MODIS vegetation indices. Remote Sensing of Environment, 83, 195-213.

Ichoku, C., Kaufman, Y. J., Giglio, L., Li, Z. Fraser, R. H., Jin, J.Z., \& Park, W. M. (2003). Comparative analysis of daytime fire detection algorithms using AVHRR data for the 1995 fire season in Canada: perspective for MODIS. International Journal of Remote Sensing, 24 (8), 1669-1690.

International Association of Oil and Gas Producers (OGP). (2000). Flaring and venting in the oil and gas exploration and production industry: An overview of purpose, quantities, issues, practices and trends. Report No. 2.79/288.

Jonsson, P., \& Eklundh, L. (2004). TIMESAT-a program for analizing time-series of satellite sensor data. Computers Geosciences, 30, 833-845.

Justice, C.O., Giglio, L., Korontzi, S., Owens, J., Morisette, J.T., Roya, D., Descloitres, J., Alleaume, S., Petitcoline, F., \& Kaufman, Y. (2002). The MODIS fire products. Remote Sensing of Environment 83, $244-262$.

Justice, C., Giglio, L., Boschetti, L., Roy, D., Csiszar, I., Morisette, J., \& Kaufman, Y. (2006). Algorithm Technical Background Document: MODIS Products. http://modis.gsfc.nasa.gov/data/atbd/atbd_mod14.pdf. (accessed on 10th March, 2011).

Kaufman, Y.J., Justice, C., Flynn, L., Kendall, J., Prins, E., Ward, D. E., Menzel, P., \& Setzer, A. (1998). Monitoring Global Fires from EOS-MODIS. Journal of Geophysical Research, 103, 32215-32338. 
Lanorte, A., Danese, M., Lasaponara, R., \& Murgante, B. (2011). Multiscale mapping of burn area and severity using multisensor satellite data and spatial autocorrelation analysis. International Journal of Applied Earth Observation and Geoinformation xxx, $\mathrm{xxx}-\mathrm{xxx}$

Li, Z., Kaufman, Y.J., Ichoku, C., Fraser, R., Trishchenko, A., Giglio, L., Jin, J., \& Yu, X. (2000). A review of AVHRR-based active fire detection algorithms: principles, limitations, and recommendations. http://www.fao.org/gtos/gofc-gold/docs/fire_ov.pdf. (accessed on 4th February, 2011).

Martín. M. P., Flasse, S., Downey, I., \& Ceccato, P. (1999). Fire detection and fire growth monitoring using satellite data. http://publiclibrary.rfs.nsw.gov.au/CommonDocuments/7300FiredetectionMicrosoft\%20Word\%20\%20review.pdf. (accessed on 10th March, 2011).

Matson, M. and Dozier, J. (1981). Identification of subresolution high temperature sources using a thermal IR sensor. Photogrammetric Engineering and Remote Sensing, 47:1311.

MODIS Characterization Support Team. (2012). MODIS Level 1B In-Granule Calibration Code (MOD_PR02) High-Level Design. MCST Internal Memorandum \# M1057 - REV. B. http://mcst.gsfc.nasa.gov/sites/mcst.gsfc/files/file_attachments/M1057_HighLevel Design 082212 REV B final xg.pdf (accessed on 2nd July, 2014).

Movaghati S., Samadzadegan F., \& Azizi A. (2009). An Agent-Based Approach for Regional Forest Fire Detection using MODIS Data. Journal of Applied Sciences 9 (20), 3672 - 3681.

Muirhead, K., \& Cracknell, A.P. (1984). Identification of gas flares in the North Sea using satellite data. International Journal of Remote Sensing, 5 (1), 199 - 212.

National Petroleum Investment Management Services (NAPIMS) (2010). NNPC/AGIP JV to commence 2nd phase of Kwale-Okpai IPP soon. http://dev.nnpcgroup.com/napims/AboutUs/NAPIMSNews/tabid/245/articleType/ArticleView/articleI d/246/NNPCAGIP-JV-TO-COMMENCE-2ND-PHASE-OF-KWALE-OKPAI-IPP-SOON.aspx. (Accessed on 9th, March, 2014).

National Population Commission (NPC). (2010). 2006 Population and Housing Census: population distribution by sex, state, LGA and senatorial district.

Nigerian Liquefied Natural Gas at Bonny Island - NLNG. (2013). Our Company: History. http://www.nlng.com/PageEngine.aspx?\&id=44 (accessed on $24^{\text {th }}$ October, 2013).

Nigeria National Petroleum Corporation - NNPC. (2010). Annual statistics bulletin. www.nnpcgroup.com . accessed on 10 $0^{\text {th }}$ March, 2012).

Obia, A.E., Okon, H.E., Ekum, S.A., Eyo-Ita, E.E., \& Ekpeni, E.A. (2011). The influence of gas flare particulates and rainfall on the corrosion of galvanized steel roofs in the Niger Delta, Nigeria. Journal of Environmental Protection, 2, 1341-1346 doi:10.4236/jep.2011.210154.

Odjugo, P.A.O., \& Osemwenkhae, E.J. (2009). Natural gas flaring affects microclimate and reduces maize (Zea mays) yield. International Journal of Agriculture and Biology, 11: 408-412.

Onwuka, S. (2003). Nigeria: Shell builds locally fabricated flow station. Daily Champion Newspaper (29th September, 2003).

Oseji, O.J. (2011). Environmental impact of gas flaring within Umutu-Ebedei gas plant in Delta State, Nigeria. Archives of Applied Science Research, 2011, 3 (6):272-279.

Ovri, J.E.O. Iroh, M. (2013). Corrosion Effect of Gas Flaring On Galvanized Roofing Sheet in Imo State,

Nigeria. The International Journal of Engineering and Science, 2 (1), 339-345.

Ovuakporaye, S.I., Aloamaka, C.P., Ojieh, A.E., Ejebe, D.E. \& Mordi, J.C. (2012). Effect of Gas Flaring on Lung Function among Residents in Gas Flaring Community in Delta State, Nigeria. Research Journal of Environmental and Earth Sciences, 4(5), 525-528.

Paki, F.A.E., \& Ebienfa, K. I. (2011). Militant Oil Agitations in Nigeria's Niger Delta and the Economy. International Journal of Humanities and Social Science, 1 (5), 140-145.

Prins, E.M., \& Menzel, W.P. (1992). Geostationary satellite detection of biomass burning in South America. International Journal of Remote Sensing, 13 (15), 2783-2799.

Punch Nigerian Newspaper. (2009). Upsurge of Militancy in Niger Delta. http://archive.punchng.com/Articl.aspx?theartic $=$ Art20090303762220. (accessed on $20^{\text {th }}$ October, 2011).

Qian, Y., Yan, G., Duan, S., \& Kong, S. (2009). A Contextual Fire Detection Algorithm for Simulated HJ1B Imagery. Sensors, 9, 961-979. 
Roberts, G. Wooster, M. J., Perry, G. L. W., Drake, N., Rebelo, L.M., and Dipotso, F. (2005). Retrieval of biomass combustion rates and totals from fire radiative power observations: Application to southern Africa using geostationary SEVIRI imagery. Journal of Geophysical Research, 110 (D21111), 1 - 19.

Roberts, G.J., \& Wooster, M.J. (2008). Fire detection and fire characterization over Africa using Meteosat SEVIRI. IEEE Transactions on Geoscience And Remote Sensing, 46 (4), 1200 - 1218.

Royal Geography Society. (2013). Spearman's rank correlation coefficient-Excel guide http://www.rgs.org/NR/rdonlyres/4844E3ABB36D4B148A203A3C28FAC087/0/OASpearmansRank ExcelGuidePDF.pdf (accessed on 15th July, 2013)

Sedano, F., Kempeneers, P., San Miguel, J., Strobl, P., \&Vogt, P. (2013). Towards a pan European burnt scar mapping methodology based on single date medium resolution optical remote sensing data. International Journal of Applied Earth Observation and Geoinformation, 20, 52-59.

Shell Petroleum Development Company of Nigeria (SPDC) (2013). Shell in Nigeria: Gas flaring. http://s02.static-shell.com/content/dam/shell-new/local/country/nga/downloads/pdf/2013bnotes/gasflaring.pdf (accessed on $9^{\text {th }}$ March, 2014).

Shell Petroleum Development Company of Nigeria (SPDC) (2011). Shell in Nigeria: The Afam VI Power Generating Plant and Okoloma NAG Facility. http://s00.staticshell.com/content/dam/shellnew/local/country/nga/downloads/pdf/2013bnotes/afam.pdf (accessed on 9th, March, 2014).

Smith, A.M.S., Wooster, M.J. 2005. Remote classification of head and backfire types from MODIS fire radiative power and smoke plume observation. International Journal of Wildland Fire, 14, 249 -254

Stoms, D.M., Bueno, M.J., \& Davis, F.W. 1997. Viewing geometry of AVHRR image composites derived using multiple criteria. Photogrammetric Engineering \& Remote Sensing, 63, 6, 681-689.

Wang, S.D., Miaoa, L.L., \& Peng, G.X. (2012). An improved algorithm for forest fire detection using HJ data. Procedia Environmental Sciences, 13, 140-150.

Weaver, J. F., Lindsey, D. T., Bikos, D. E., Schmidt, C. C., \& Prins, E. 2004. Fire detection using GOES-11 rapid scan imagery. Weather and Forecasting, 19, 496-510.

Wooster, M.J., Zhukov, B., Oertel, D. (2003). Fire radiative energy for quantitative study of biomass burning: derivation from the BIRD experimental satellite and comparison to MODIS fire products. Remote Sensing of Environment, 86, 83-107.

Wooster, M.J., Xu, W., \& Nightingale, T. (2012). Sentinel-3 SLSTR active fire detection and FRP product: Pre-launch algorithm development and performance evaluation using MODIS and ASTER datasets. Remote Sensing of Environment, 120, 236-254.

Xu, W., Wooster, M. J., Roberts, G., \& Freeborn, P. (2010). New GOES imager algorithms for cloud and active fire detection and fire radiative power assessment across North South and Central America. Remote Sensing of Environment, 114, 1876-1895.

Zhukov, B., Lorenz, E., Oertel, D., Wooster, M.J, \& Roberts, G. (2006). Spaceborne detection and characterization of fires during the bi-spectral infrared detection (BIRD) experimental small satellite mission (2001-2004). Remote Sensing of Environment, 100, 29-51.

\section{$\underline{\text { List of Figure captions }}$}

Figure 1. Map of the Niger Delta region, showing its component oil producing states. Map of Nigeria is inset.

Figure 2. Spectral band images demonstrating the gas flare detection potential of day time and nighttime MODIS band 22 and daytime band 7 (band 6 showed a very similar response). Bands 6 and 7 are turned off at nighttime.

Figure 3. Flow chart illustrating the key stages of the MODIS Flare Detection Technique (MODET), based on the harnessing of radiometric and spatial properties of flares in nighttime band 22 imagery.

Figure 4. An active flare in the Agbada oilfield (Rivers State) of the Niger Delta captured in a high resolution image on Google Earth

Figure 5. Scatterplot of the radiance of flare sites (quantified by the product of the square of the sum of radiance and standard deviation of radiance values in the buffer zone around flare pixels) and recorded volume of gas flared at sample flow stations in the Niger Delta, used for calibrating the MOVET model. 
Figure 6. Map showing the spatial distribution of flare sites identified in the Niger Delta with the MODIS Flare Detection Technique from March 2000 to January 2014. Flare sites detected once are those that are newly detected in 2013/14.

Figure 7. Flare sites detected in the Niger Delta from 2000 to 2014. The positive error bar (9.3\%) is based on the producer's accuracy of the MODET while absence of a negative error bar reflects the $100 \%$ user's accuracy.

Figure 8. The distribution of volume of gas combusted at individual flare sites (represented by the size of the symbol that shows the location of each site) and within each state (represented by the colour shading of each state) over the study period (2000-2014).

Figure 9. Trajectories of annual gas flaring volume (BCM) within the individual states in the Niger Delta over the study period, indicating the contribution of onshore (blue bars) and offshore (red bars) flaring towards each annual total.

Figure 10. Graph showing the temporal trajectory of annual flaring volume estimated using the method developed in this research compared to reported annual volumes and annual crude oil production within the study area. Error bars represent the 99\% confidence interval derived from the calibration of the MOVET. 